This chapter serves as a guide for quantitative researchers who seek to approach their research questions critically.

\title{
Bridging Key Research Dilemmas: Quantitative Research Using a Critical Eye
}

\author{
Deborah Faye Carter, Sylvia Hurtado
}

For many of us who use quantitative methodology on a regular basis, we confront constraints while at the same time attempting to stretch the boundaries of current theory and develop models relevant to specific populations. This becomes clearer over the course of a long-term research agenda, because the topics we choose and who we are as researchers become evident through our work. In this chapter, we explore several key research dilemmas and potential solutions for quantitative researchers intent on using a critical eye for examining current theory and models.

These dilemmas involve describing how the role of the quantitative researcher becomes apparent on examination of a body of work, the choice between comparing groups or highlighting variability in a single group, choosing approaches for generalizability or context specificity, and remaining "distant" or participating in action research. Finally, we propose potential solutions to some of these dilemmas, which we have confronted in our own work.

In this chapter, we argue that (1) quantitative research is not wholly objective and that there are ways in which autobiography can intersect with research; (2) critical quantitative approaches identify discrepancies between theory and fact; and (3) there are positives and negatives for comparative group versus context-specific approaches to understanding group differences.

\section{(3)WILEY}

\section{InterScience ${ }^{\circ}$}




\section{Finding the Intersection Between Autobiography and Research}

First, we insist there is an intersection of autobiography and research for quantitative researchers. Why is there no room for exploring the role of quantitative researchers in their work as there is in qualitative work? One of the main reasons for this absence is the age-old assumption that remaining an "objective" and distant researcher is preferable and lends confidence to the work. However, a great deal of quantitative research that claims to be objective really is politically motivated and perhaps biased regarding issues of race in higher education (Rothman, Lipset, and Nevitte, 2003). We would do well to know the autobiographies of quantitative researchers to judge more astutely the work at two levels: the extent to which the work is a rigorous test of a theory or hypothesis and achieves its objective and how this fits into the overall work of these researchers in their long-term goals to improve education or shift its purpose. In this chapter, we devote attention to the first level, although it may escape the scrutiny of peer review on occasion. The second level is rarely discussed or explored in formal settings.

As women of color, it is evident in our work that our main goal is to improve higher education for the success of diverse college students in a variety of contexts. In many ways, we study the underrepresented populations in higher education because of our own unique experiences in higher education. We attempt to unpack our own college experience examining hundreds and sometimes thousands of students from backgrounds not unlike our own because we understand there is something unique about that experience (and overcoming the odds of failure) that deserves explanation. We seek to educate others and test our own intuitive hypotheses about the way the world works. It drives us to develop better questions, more relevant models for diverse student populations, and to understand whether the issues of this generation of students are the same as for our own generation. With every test of a model using a distinct population, we attempt to break down the theory, document alternative experiences, and begin to construct new models (Hurtado and Carter, 1997). This cannot and should not be the work of only qualitative methodologists.

Another reason exists to explore the intersection of autobiography and research, and that is that the role of objectivity is being questioned at all levels in methodology (Harding, 1991). Krathwohl (1998) describes new ways to determine the distinction between a researcher's observations and how others may view the same phenomenon. These distinctions have yet to find their way into quantitative methods. Furthermore, quantitative methods cannot remain unchanged by recent questions raised in science, feminist studies, and advancements in qualitative methodology. For example, critical theories and qualitative approaches question the notion of objectivity, how best to represent multiple perspectives, and how the researcher is involved in the design and interpretation of findings. 
We acknowledge, however, that there are strong pressures for consensus about research approach and how one employs the scientific method in educational research, which come essentially from a field that is in the midst of struggle about whether or not there is a predominant paradigm. In the Structure of Scientific Revolutions, Kuhn (1996) states that paradigm-based research is "an attempt to force nature into the preformed and relatively inflexible box" (p. 24). When researchers in a field attempt to establish consensus about a prevailing paradigm, there is little effort to call forth new sets of phenomena. Further, there are few attempts to discover anomalies, and when they do emerge, they are discarded or overlooked. For example, how many times have we ignored the fact that our models typically are less likely to explain one group's behavior when compared with another (for example, examining the variance explained in educational outcomes for black females when compared with white females or men)?

Moreover, "normal scientific research is directed to the articulation of those phenomena and theories that the paradigm already supplies" (Kuhn, 1996, p. 24). This suggests that the challenge is simply in figuring how to solve a puzzle for an answer that we are almost sure already exists. It also suggests very little interest in new theory development, or modification of existing theories, and presupposes that we already know the theories to test. The focus then becomes confirmation and replication and not on generating new models or ways of thinking about the important issues and relevance to the improvement of practice. This is a central dilemma, particularly now that the U.S. Department of Education has attempted over the last few years to push experimental research as the predominant and "valid" research approach in education. It provides evidence of pressure to restrict the researcher's vision, apply rigid rules of science, resist varied forms of epistemology, and neglect dynamic conditions in the field of practice. In important areas of practice that involve inequity in education and achievement, it may not yet be possible to improve the educational problems we observe within the confines of what is known or within the frames of current theory. New discoveries are necessary and are only possible by training researchers to maintain a critical eye for new phenomena.

\section{Identifying Discrepancies Between Theory and Fact}

Kuhn (1996) suggests that we can employ normal science and advance discovery by paying attention to discrepancies between theory and fact. That is, we can come up with a series of facts that no longer fit our theories and begin to call into question the existing theory, urge its modification, or encourage new theory building. We can do so when adopting new models and measures that might help explain the experiences of particular groups, especially those whose educational experiences and achievement we are interested in improving. This was the approach we took in attempting to 
understand Latino students' sense of belonging in college (Hurtado and Carter, 1997).

In that study, we sought to test conceptually how Latino students experience integration into the college community. Tinto's 1993 theory makes a distinction between student participation in academic and social systems in colleges and universities and academic and social "integration." Further, we argued that the notion of integration may be distinct still from students of color who are entering predominantly white college environments.

The core issues we explored were the distinction between students' psychological sense of their membership in the campus community and their actual participation in campus life. With respect to students' actual participation in campus life, we posited that students of color attending predominantly white institutions must interact in multiple worlds (that of their own cultural group and that of other cultural groups) and therefore often have multiple memberships in campus communities.

As a result of our study, we advocated departures from Tinto's model to allow for greater understanding of students' transitional dilemmas, how campus programs can help students adjust to the college experience, and how students' memberships in various communities contribute to the concept of cohesion or marginalization on campuses.

Quantitative researchers face other dilemmas that can also be decided to help devote greater attention to anomalous phenomena that may lead to advancements of practice and our understanding of educational issues. These include determining when to use a comparative group versus a group-specific approach to a research issue, choosing an approach to highlight generalizability of findings or to highlight the findings specific to a particular context, and determining when to conduct research "objectively" distanced or to participate in action research. In addition, the uses of new theory can lead to new ways of looking at an issue that have remained unexplained or examined in previous work. The advantages and disadvantages of each approach are explained and, finally, ways to resolve such dilemmas are highlighted at the end of the chapter.

Using a Comparative Group Approach Versus a Group-Specific Focus. A typical mechanism for examining group differences is to use dichotomous variables in a regression model or an analysis of variance (ANOVA) to determine differences. One advantage to developing a single statistical model and using dichotomous variables to examine group differences or ANOVA is that a single model may apply to various groups of students. For research studies that have smaller sample sizes, the study may not have appropriate statistical power if separate group analyses are performed.

There are some limitations to using single statistical models to examine group differences. Although using dichotomous variables can account for some differences, in statistical models where several variables differ across racial and ethnic groups, a single statistical model can eclipse the cir- 
cumstances under which some variables may differ across groups. It is true that interaction terms can help tease out specific effects, but what if there are many independent variables in the model? This requires a hypothesis or rationale for each interaction term. We believe it is not practical to construct dozens of interaction terms and that a comparative group approach may be needed instead in order to conduct a more complex investigation of group differences.

Comparative Group Approach. The comparative group approach refers to the method of conducting statistical analyses separately by group. There has been research that suggests that minority groups experience achievement processes in a different manner than white students. The comparative group approach would involve examining achievement processes separately by racial or ethnic group. This is an appropriate technique if the researcher already knows (based on previous research) that there are likely to be group differences and that something useful can be gleaned from completing the analyses separately. The benefit of separate group analyses is that variables that affect groups differently can be clearly seen. Some variables may have strong positive effects for one group but no significant effect or a negative effect for another group.

Another benefit of comparative group analysis is that it can provide a context for understanding findings. For instance, St. John (1991) found that African Americans are less likely to attend college than White students, but that after taking into account degree aspirations, African American students are as likely (or perhaps more likely) to attend college. This indicates that there are important social and contextual variables that can be eclipsed if comparative analyses are not performed or groups of students are analyzed together.

A limitation of separate group analyses is that it may be difficult to compare groups if the sample sizes are uneven. Some adjustment to statistical coefficients may need to be made to make valid comparisons. Also, in the need to construct comparable statistical models across groups, the individual groups may not receive enough attention. For instance, there may be some factors affecting certain student groups that have little relevance for the compared groups-but these factors need to be included in all comparative group models so useful comparisons can be made. For instance, "Language Spoken at Home" could yield different results for African American populations than for Asian American or Latino groups. Comparing results on that measure across groups will necessitate explanation and interpretations that are specific to certain groups.

Specific Group Approach. Another approach is to focus research on a specific group. For instance, a researcher may decide to study only the Latino population. A strength of this approach in quantitative research is that more of the group's internal variability can be examined. A researcher could intentionally sample various ethnicities in that population (for example, Puerto Rican, Mexican, Brazilian, Cuban, El Salvadoran, and so on) to 
study how they differ. Using this research approach, researchers may be able to employ more complex analyses to understand within-group heterogeneity as well as how such issues as generation status and language spoken at home uniquely affect the different ethnic groups.

\section{Choosing an Approach for Generalizability or for Context Speci-}

ficity. In judging quantitative research, one of the key considerations is its generalizability. In designing a study, we often pay attention to careful selection of types of institutions and of student populations in those institutions to ensure both representation and generalizability. We have more confidence in findings that may hold true across a number of contexts and that represent some standard of universal truth. It is the preferred research standard. If it is not generalizable, we expect the quantitative researcher to state the limitations of the study and explain how these findings may not be applicable to all students in all higher education settings. It is important to note that, on average, the generalizable findings will hold for all students and institutions; however, researchers are less likely to emphasize how the findings might be variable. Instead, we simply encourage others to replicate the work to confirm its generalizability across contexts and populations. Educational research has recently come under criticism for far fewer replication studies than in other fields (Berliner, 2002), so it may be less likely that our findings will be confirmed in a reasonable time frame. In short, we need to recognize that the issue of generalizability remains an important but rather elusive goal in practice.

Researchers not only neglect to mention when their studies may fail to apply to students outside of "the average" but tend to view such departures as anomalies. We contend that perhaps the most interesting part of a study may indeed be these departures. They require closer examination and insist on a more critical eye. Departures from average norms suggest habits or experiences of students that cannot conform to "one-size-fits-all" higher education settings and practices. Taking note of these departures may be critical to improving practice.

This leads us to another consideration in choosing a research approach to address generalizability-that is, it may be more difficult to adapt an "average finding" to practices that are typically contextual. There can be a gap between what the research says works and what really works in practice (we return to this issue in a subsequent section). It is even more dangerous to assume that findings in one context or study are applicable in another context - the true test of generalizability must provide evidence that a finding is indeed applicable in other contexts and student populations. For example, increasing students' social integration to improve student retention is not as possible at a community college as it is at a four-year residential college; one reason is that working students do not rely on college for social activities. Yet the assumption is that social integration is such a universal proposition that it must be enacted at all institutions. Much more 
research is needed on the specific context to determine the unique institutional and experiential elements of student retention for community college students-and it is highly likely the answer lies inside rather than outside the classroom.

Generalizability must be linked back to context if we seek to improve education, and this provides some support for conducting context-specific studies without apologies for lack of generalizability. In fact, a contextspecific study can be rationalized that it contributes to understanding generalizability because there is some doubt about the universality of published findings until proven applicable in a variety of contexts. Context-specific studies can then be used to question widely accepted models and findings that inform practice, provide insight into departures from theses theories and research findings, and begin to suggest unique models. The contextspecific approach also allows for stronger links with actual practices in institutions. Here is where institutional research is important in the grand scheme of educational research: it can be informed by prevailing theories and research but also more finely attuned to the need to improve practices in specific institutional contexts. It is decidedly context-specific and plays an important role in understanding the universality of truths we uncover in our efforts to improve postsecondary education.

There are some important cautions to consider in a context-specific approach. First, some models are developed for single institutions and these may be too unique to adapt to other contexts. We need to require researchers to highlight these unique aspects of the context in which their study is conducted. This allows others to judge whether a similar study or its findings are applicable to other contexts. For many researchers not engaged in institutional research, where there exists a great deal of familiarity with the context, a context-specific approach requires more field-intensive work to grapple with the unique culture and climate and student body at the institution. This information needs to be shared with readers of the published research.

Second, context-specific studies still need to adhere to methodological rigor, even if the setting focuses on a specific group or groups or environment. Braxton, McKinney, and Reynolds (2006) surveyed the retention data from a few dozen colleges and universities and concluded that most of the studies did not employ sufficient methodological rigor-either in terms of using appropriate multivariate statistical tests or the use and application of theory. Important quantitative work can be done with a critical eye, and such work needs to remain methodologically sound.

\section{Conducting Research Objectively or Participating in Action}

Research. Many of the quantitative educational research traditions are based on the scientific method. These traditions (which are also referred to as postpositivist) focus on examining "causes that influence outcomes" (Creswell, 2002, p. 7). Most quantitative research begins with testing a 
particular theory even if a postpositive perspective acknowledges that there is no absolute truth and that no research study or research methods are perfect. However, postpositive frameworks still assume objectivity in the research and most researchers "must examine their methods and conclusions for bias" (p. 8).

Although a core assumption of the scientific method and postpositivism is that of objective orientation, this assumption may not be accurate. Researchers have particular assumptions and biases that can affect the kinds of measures used, the data collected, the participants involved in the research, the statistical methods used, and the interpretations of the results. Two theoretical approaches that are often associated with qualitative research can be applied to quantitative approaches as well: critical race theory and action research.

Critical theories - theories that critically examine social roles and institutions-are gaining recognition in higher education research. One example of a critical theory is critical race theory (CRT).

\begin{abstract}
Critical [race] theory is a framework or set of basic insights, perspectives, methods, and pedagogy that seeks to identify, analyze, and transform those structural and cultural aspects of higher education that maintain the marginal position and subordination of [people of color]. . . . Critical race theory suggests that while those on the social margins have less access to opportunities and resources, they also experience different barriers, obstacles, or other forms of individual and societal oppression than those at the center. (Solórzano and Villalpando, 1998, pp. 212-214)
\end{abstract}

Many researchers have used CRT frameworks for qualitative methods (see Solórzano, 2001, for one example), but the philosophical framework can be applied to quantitative research as well. It is possible to examine phenomena with objectivity and weigh alternative explanations where appropriate while also advocating for social justice and for the reduction of racism.

Action research-like critical race theory-advocates for the researcher becoming immersed in the research and using that research to inform changes in practice (McNiff, 2002). A key element of action research is the feedback between the researcher-practitioner and the system being researched. Once phenomena are identified and studied, recommendations for changes in practice are developed and the effect of these changes can then be studied. All of this forms a constant loop of activity in which the researcher-practitioner can be constantly engaged. Research as a catalyst for change or a form of advocacy is not a new approach, but this approach can be an effective means for conducting quantitative research on marginalized groups and for populations where simultaneous interventions and research are needed. 


\section{New Directions for Quantitative Research}

How have we begun to bridge these research dilemmas? Although we have provided some directives in our explanation of these dilemmas, here we summarize potential solutions that are derived from our own work. First, although we insist there is an intersection of autobiography and research for users of quantitative methodology, our field is far from accepting the notion that we should lay bare the biases we bring into the research process even as it has become more standard practice for qualitative researchers who serve as the "instruments" of data collection, analysis, and interpretation. There is still the notion that we should be free of politics to engage in the search for truth, and we wish to preserve such autonomy. However, at the same time, education (its funding, administration, and implicit assumptions that underlie practice) is not entirely free of politics and it would be a mistake to think our research occurs independently of these political debates or our own frames of reference that come from our educational, professional, and social backgrounds.

We do encourage all researchers to begin to share this information, just as we have attempted to share here our long-range goals and hopes for educational improvement. We can begin to explain more about the intent, motivations, and objectives of our approach and to take responsibility for the aims we wish to achieve (such as improving educational opportunity for students of color) without compromising rigor, replicability, and responsibility. The role of the researcher is important, but should not be privileged or overemphasized at the expense of the important research questions that merit careful and rigorous examination. We are also frank in acknowledging that some of our audiences, intent on finding answers or information, such as the users of institutional research, simply do not care to know the researcher. So the solution involves knowing one's audience and finding a place to insert the role of quantitative researcher where appropriate. For those of us with professional higher education experiences, it can even lend credence to research in its link with practice.

If we see each research dilemma presented here as an either-or decision or proposition, a viable solution is not possible. It is important to acknowledge flexibility in research design to allow something in between for wider use of our findings. For example, if most studies select either a comparative group approach or group-specific approach, there is still room for a solution that bridges these approaches in creating a new design. One such design may use a comparative study to focus a group-specific approach. This involves conducting analysis on the entire population and on a specific population of interest as well, to determine whether unique models are required, and then providing further explanation about these departures. For studies lacking the same data on a more general population, another solution is to provide an adequate review of research that has generated "normative" findings as a backdrop for exploring how a specific population conforms or 
departs substantially from traditional models or research focused on more general populations (Hurtado and Carter, 1997).

These solutions parallel another approach that can be used to address generalizability and context specificity. For example, for many years the Cooperative Institutional Research Program (CIRP) has encouraged institutions to use its surveys to examine their own environments and compare themselves to national, normative data or peer institutions (Higher Education Research Institute, 2005). This is extremely useful for institutional researchers, and the cooperative nature of the design allows for these helpful comparisons to decide if a student body at a particular campus is unique or much like the average across the nation. Further breakdowns of the data can determine if this is true for specific student populations as well. It addresses the needs of context-specific information and more universal principles of student behavior, values, skills, and attitudes. Consortia or collaborating institutions share data to discover what works across the campuses and what may work on their own particular campuses. More recently, general research on public universities provides a backdrop for the individual collaborating institutions to examine their own student experiences and models for improving undergraduate education (Hurtado, 2003). Meetings were held with members of all participating campuses to also share practices to achieve key undergraduate education goals.

Still another solution is to mix quantitative methodology (for providing an overview of issues and concerns) with qualitative methodology (for exploring contexts and specific populations in-depth) when knowledge about specific issues and concerns is lacking. Clearly quantitative methods are best suited when we can anticipate questions to ask and theory to test. However, we may still have difficulty interpreting results without information about context or student experiences. This is where qualitative research can be helpful to inform the findings. Using a mixed-method research design can help us achieve goals for generalizability and context specificity, allowing us to assume a more critical eye toward the limitations of what we can know for each technique.

The final dilemma on achieving distance as opposed to engaging in action research forces us to identify ways to convert research into improvements in practice. Action research is more often used in the case of interventions, corrections based on results, and revision of interventions. If we are not charged with implementation of intervention or its evaluation, we should find ways to partner with practitioners who will implement the research findings. At the very least, we should step out of our roles as distant researchers on occasion to encourage the use of research findings in improving practice. This involves putting our research into the hands of those who need the information, and evaluating our work by the impact it has on actual educational practice. 


\section{References}

Berliner, D. C. "Educational Research: The Hardest Science of All." Educational Researcher, 2002, 31(8), 18-20.

Braxton, J. M., McKinney, J. S., and Reynolds, P. "Cataloging Institutional Efforts to Understand and Reduce College Student Departure." In E. P. St. John and M. Wilkersons (eds.), Reframing Persistence Research to Improve Academic Success. New Directions for Institutional Research, no. 130. San Francisco: Jossey-Bass, 2006.

Creswell, J. W. Research Design: Qualitative, Quantitative, and Mixed Methods Approaches. Thousand Oaks, Calif.: Sage, 2002.

Harding, S. "Whose Science? Whose Knowledge? Thinking from Women's Lives." Ithaca, N.Y.: Cornell University Press, 1991.

Higher Education Research Institute. The American Freshman: National Norms for 2004. Los Angeles: University of California, 2005.

Hurtado, S. "Are We Achieving the Promise of Diversity?" Liberal Education, 2003, 88(2), $12-13$.

Hurtado, S., and Carter, D. F. "Effects of College Transition and Perceptions of the Campus Racial Climate on Latino College Students' Sense of Belonging." Sociology of Education, Oct. 1997, 70, 324-345.

Krathwohl, D. R. Methods of Educational and Social Science Research: An Integrated Approach. (2nd ed.) Reading, Mass.: Addison-Wesley, 1998.

Kuhn, T. S. The Structure of Scientific Revolutions. (3rd ed.) Chicago: University of Chicago Press, 1996.

McNiff, J. Action Research: Principles and Practice. London: Routledge, 2002.

Rothman, S., Lipset, S. M., and Nevitte, N. "Racial Diversity Reconsidered." Public Interest, Spring 2003, 151, 25-38.

Solórzano, D. G. "Critical Race Theory, Racial Microaggressions, and Campus Racial Climate: The Experiences of African American College Students." Journal of Negro Education, 2001, 69(1), 60-73.

Solórzano, D. G., and Villalpando, O. "Critical Race Theory, Marginality, and the Experience of Students of Color in Higher Education." In C. A. Torres and T. R. Mitchell (eds.), Sociology of Education: Emerging Perspectives. Albany: State University of New York Press, 1998.

St. John, E. P. "What Really Influences Minority Attendance? Sequential Analyses of the High School and Beyond Sophomore Cohort." Research in Higher Education, 1991, 32(2), 141-158.

Tinto, V. Leaving College: Rethinking the Causes and Cures of Student Attrition. (2nd ed.) Chicago: University of Chicago Press, 1993.

DEBORAH FAYE CARTER is associate professor and director of the Center for the Study of Higher and Postsecondary Education at the University of Michigan.

SYLVIA HURTADO is professor in the Graduate School of Education and Information Studies and director of the Higher Education Research Institute at the University of California, Los Angeles. 